ORIENTAL JOURNAL OF CHEMISTRY

An International Open Access, Peer Reviewed Research Journal

www.orientjchem.org
ISSN: 0970-020 X

CODEN: OJCHEG

2021, Vol. 37, No.(2):

Pg. 440-443

Brief communication

\title{
Influence of Temperature on the Rheological Behavior of Orange Honey
}

\author{
IOANA STANCIU \\ Department of Physical Chemistry, Faculty of Chemistry, University of Bucharest, \\ 4-12 Elisabeta Blvd, 030018, Bucharest, Romania. \\ *Corresponding author E-mail: istanciu75@yahoo.com \\ http://dx.doi.org/10.13005/ojc/370225
}

(Received: February 08, 2021; Accepted: March 19, 2021)

\begin{abstract}
The study was performed to determine the effect of the logarithm of the viscosity on the inverse of the absolute temperature for orange honey. Based on the studied rheograms, it turned out to be a non-Newtonian fluid. The shear range used did not significantly affect the absolute viscosities of orange honey at different temperatures. The absolute viscosities of orange honey have decreased with increasing temperature and can be equipped with an Arrhenius type relationship. The rheological behavior is influenced by both humidity and its composition.
\end{abstract}

Keywords: Rheology, Orange Honey, Temperature.

\section{INTRODUCTION}

Honey is a natural product, consumed as food since ancient times ${ }^{1}$. The special status of honey for consumers is due to its natural product image and health benefits ${ }^{2,3}$. After some scandals over honey, its quality by origin has become associated with consumer expectations. For example, in the European Community, counterfeit Chinese honey with high fructose corn syrup has been found, with other incidents involving the discovery of an excessive residue of antibiotic residue in honey from third world countries ${ }^{4}$. Therefore, quality standards emphasize the importance of honey quality by origin, and this is used in promoting sales through specific labeling. Labels such as monoflora or polyflora, organic, with a protected designation of origin, meet the requirements of the consumer, as well as those of the honey industry and control bodies. In addition, researchers are required to provide methods and markers that link honey to existing regulations.

The specifications of honey with geographical indication are generally based on physico-chemical parameters. These indicators have been shown to have limited potential in determining the origin of honey. Consequently, the discovery of chemical markers to help determine the quality of honey by origin, has been the subject of many studies in recent times. This includes studies dealing with volatile compounds ${ }^{5}$, phenolic compounds ${ }^{6}$ and the mineral content ${ }^{7}$ of honey of different floral and geographical origins. The most recent and comprehensive study of this kind is the one written

This is an Open Access article licensed under a Creative Commons license: Attribution 4.0 International (CC- BY). Published by Oriental Scientific Publishing Company @ 2018

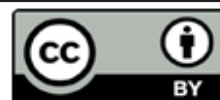


by Kaskoniene et al., 2010,8 study that provides excellent results trying to define typical compounds that are best associated with the origin of honey. Within the Trace project, natural markers of honey, such as minerals ${ }^{9}$, the ratio of (bio) isotopes and genetic markers were determined to determine the geographical, botanical and production origin ${ }^{10-16}$.

This article presents $\ln \eta$ versus $1 / \mathrm{T}$ on the rheological behavior of orange honey. Honey was studied in the temperature range $25-45^{\circ} \mathrm{C}$ and humidity of $16 \%, 17 \%, 19 \%$ and $21 \%$.

\section{MATERIAL AND METHODS}

The orange honey studied in this article comes from Greece. A study was performed to determine the effect of shear rates (3.3 to $120 \mathrm{~s}^{-1}$ ) on shear stresses for orange honey at temperatures between $\left(25\right.$ to $45^{\circ} \mathrm{C}$ ). The absolute viscosities of the orange honey were determined using a Haake VT 550 viscometer, a rotary viscometer with coaxial cylinder $\mathrm{HV}_{1}{ }^{17}$.

\section{RESULTS AND DISCUSSION}

Often, in technological processes, in order to improve the flow characteristics so as to facilitate the pumping, mixing, filling of containers, higher temperatures are used for the processed fluids. In liquids, viscosity is controlled by molecular cohesion forces and therefore the mobility of molecules increases by reducing the intensity of intermolecular forces, which explains the decrease in viscosity as the temperature increases. Hence the importance of strict temperature control when measuring viscosity or dependence $\tau=f(\gamma)$.

It is the viscosity dependent on temperature and can be substantial, the change being up to $10 \%$ ${ }^{\circ} \mathrm{C}$. The expression of Arrhenius equation:

$\eta=A \cdot \mathrm{e}^{\frac{E_{a}}{R T}}$

In this expression $\mathrm{E}_{\mathrm{a}}\left(\mathrm{J} . \mathrm{K}^{-1} \mathrm{~mol}^{-1}\right)$ represents the activation energy for viscosity, $\mathrm{A}(\mathrm{Pa} . \mathrm{S})$ is a proportionality factor, R-universal gas constant, $\mathrm{T}(\mathrm{K})$-absolute temperature, $\eta$ (Pa. s)-viscosity Newtonian fluid.

Because the activation energy, $E_{a}$, is the energy barrier that must be overcome for flow to occur, this parameter can be correlated with the association of liquid molecules. A high value for the activation energy suggests a strong association, as well as the fact that a large amount of energy is required to achieve the dissociation necessary to initiate the flow.

Parameter A having the unit of measurement of viscosity should represent a viscosity. Theoretically, it would be the viscosity reached by the product at infinite temperature. But as this is not feasible, it was agreed that $A$ is only a factor of proportionality.

By logarithm, relation (1) can be linearized:

$\ln \eta=\ln \mathrm{A}+\frac{\mathrm{E}_{\mathrm{a}}}{\mathrm{R}} \cdot \frac{1}{\mathrm{~T}}$

Written in this form, mathematically addictive $\ln \eta=\mathrm{f}\left(\frac{1}{\mathrm{~T}}\right)$ is a right in which $\ln A$ is found at the intersection with the ordinate, and $\frac{\mathrm{E}_{\mathrm{a}}}{\mathrm{R}}$ it is the very slope of the right. Therefore, the graphical representation of this dependence allows the graphical determination of the two parameters $A$ and $E_{a}$, from the intersection with the ordinate, respectively from the slope of the line. Obviously, the two parameters In $A$ and $\frac{E_{a}}{R}$ they can also be calculated by linear regression.

If a slight curvature (concavity) occurs near the ordinate, this suggests that there are strong secondary bonds in Newtonian fluid. In this situation, only the temperature range in which the curve is linear is chosen, and the value pairs $A$ and $E_{a}$ are associated with this temperature range. It is thus possible to predict the viscosity of a Newtonian fluid at any temperature in the linear range of the dependence $\ln \eta=f\left(\frac{1}{T}\right)$.

If we write the equation (1) for two decks, one of reference, for which the values of viscosity $\eta_{r}$ at the reference temperature $T_{r}$ are known, as well as for the unknown value of viscosity $\eta_{x}$ at temperature $T_{x}$, by dividing the two expressions we eliminate In $A$, and by logarithm the expression is obtained that allows the calculation of the viscosity $\eta_{\mathrm{x}}$ :

$\ln \frac{\eta_{\mathrm{x}}}{\eta_{\mathrm{r}}}=\frac{\mathrm{E}_{\mathrm{a}}}{\mathrm{R}} \cdot\left(\frac{1}{\mathrm{~T}_{\mathrm{x}}}-\frac{1}{\mathrm{~T}_{\mathrm{r}}}\right)$

Using this relationship involves knowing the value of the activation energy for the Newtonian fluid studied.

The influence of temperature on an assortment of honey obtained from orange blossoms at different unit contents is presented in the following 
graphs ${ }^{18}$. For the calculation of the parameters $A$ and $E_{a}$ we graphically represented the logarithm of the viscosity values and the inverse of the temperatures (expressed as absolute temperatures) and we obtained the pairs of points that allowed the graphical representation of the dependence $\ln \eta=f\left(\frac{1}{T}\right)$.

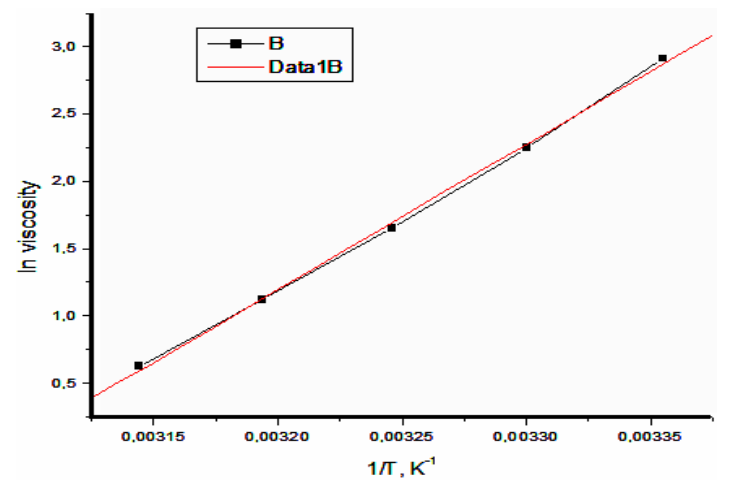

Fig.1. Linearization In versus $1 / \mathrm{T}$ of an orange honey assortment, with a moisture content of $16 \%$ for the temperature range $25-45^{\circ} \mathrm{C}$

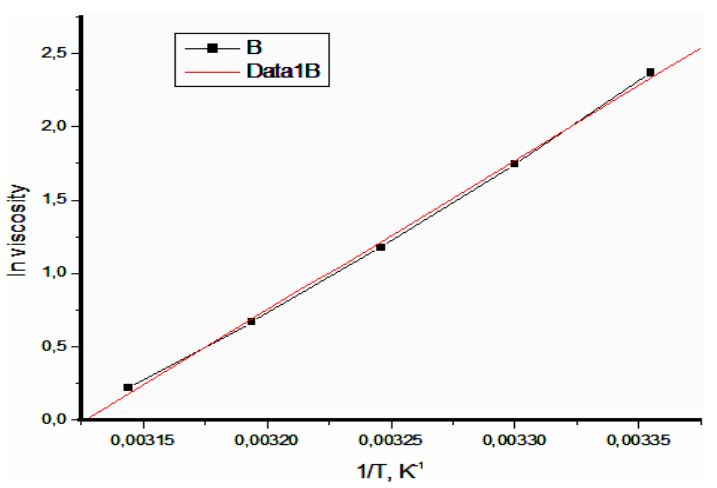

Fig. 2. Linearization In versus $1 / \mathrm{T}$ of an assortment of honey from oranges, with a moisture content of $17 \%$ for the temperature

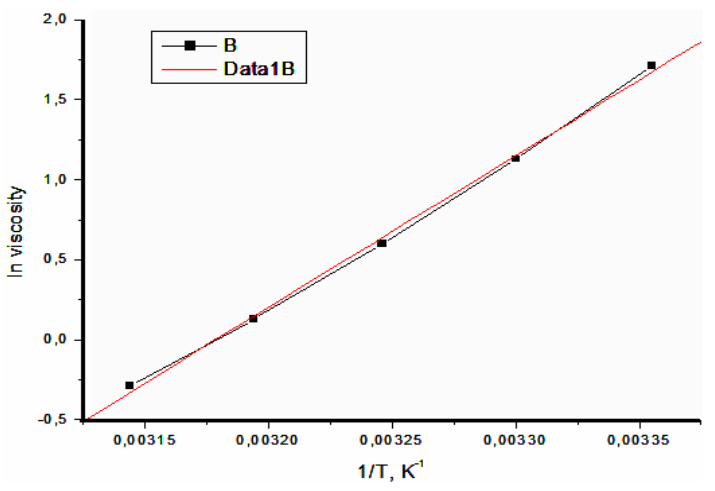

Fig. 3. Linearization In versus $1 / \mathrm{T}$ of an assortment of honey from oranges, with a moisture content of $19 \%$ for the temperature range $25-45^{\circ} \mathrm{C}$

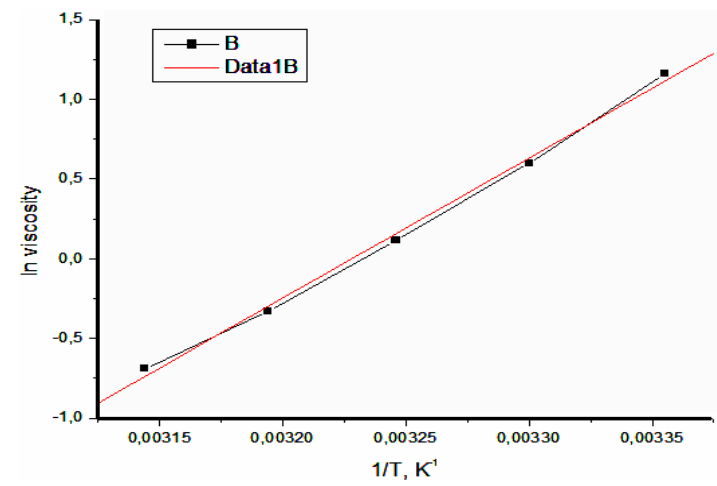

Fig. 4. Linearization In versus $1 / \mathrm{T}$ of an assortment of honey from oranges, with a moisture content of $21 \%$ for the temperature range $25-45^{\circ} \mathrm{C}$

By the linear regression applied to the lines 1, 2, 3 and 4, it was possible to obtain the values for In $A$ at the intersection of the linear regression line with the ordinate, respectively for $\frac{E_{a}}{R}$ from the slope of the regression line. By cologaritmare the value of $A$ is calculated, and from the product of the slope with the value of the universal gas constant $(R)$ the value of the activation energy $E_{a}$ is calculated. The obtained results are presented in Table 1. It is observed from the table that the values of the two parameters $A$ and $E_{a}$ are influenced by the moisture content of the honey.

Table 1: Values obtained by nonlinear regression for parameters $A$ and $E_{a}$ in the case of an assortment of honey from potrocale at different moisture contents, for the temperature range $25-45^{\circ} \mathrm{C}$

\begin{tabular}{cccc}
\hline $\begin{array}{c}\text { Moisture } \\
\text { content (\%) }\end{array}$ & Ea (kJ. mol $\left.{ }^{-1}\right)$ & $\mathrm{A}(\mathrm{Pa} . \mathrm{s})$ & $\mathrm{R}$ \\
\hline 15.9 & 89.94 & $3.03 .10-15$ & 0.9992 \\
17.0 & 84.76 & $1.42 .10-14$ & 0.9990 \\
19.0 & 78.90 & $7.89 .10-14$ & 0.9988 \\
21.0 & 73.17 & $4.56 .10-13$ & 0.9981 \\
\hline
\end{tabular}

In the case of non-Newtonian fluids, temperature is expected to influence their flow behavior. In the case of pseudoplastic fluids, the temperature influences the value of the consistency coefficient $K$, but its influence on the behavior index $n$ is insignificant. This means that by heating or cooling, if no fluid transformations occur, the pseudoplast character does not change.

Because in non-Newtonian fluids the apparent viscosity is also influenced by the shear rate, the effects of temperature and shear rate have been combined in a single expression ${ }^{17-24}$ : 
$\eta=f(T, \dot{\gamma})=K_{T} \exp \left(\frac{E_{a}}{R T}\right)(\dot{\gamma})^{\bar{n}-1}$

As in expression (1), and in expression (4) $\mathrm{K}_{\mathrm{T}}$ is a proportionality factor, even if it has the unit of measurement of the consistency coefficient $\left(\mathrm{Pa} . \mathrm{S}^{\mathrm{n}}\right)$. By amplifying the relation (4) with the shear speed, the influence of the temperature on the shear stress will be obtained:

$\tau=\mathrm{f}(\mathrm{T}, \dot{\gamma})=\mathrm{K}_{\mathrm{T}} \exp \left(\frac{\mathrm{E}_{\mathrm{a}}}{\mathrm{RT}}\right)(\dot{\gamma})^{\overline{\mathrm{n}}}$

From these two relations it can be seen that even in the case of the consistency coefficient the temperature has a logarithmic influence, of the form:

$$
\mathrm{K}=\mathrm{K}_{\mathrm{T}} \exp \left(\frac{\mathrm{E}_{\mathrm{a}}}{\mathrm{RT}}\right)
$$

\section{CONCLUSION}

The effect of In versus $1 / T$ of honey showed that the viscosity of honey decreases with increasing temperature and best modeled with the Arrhenius equation.

This article presents influence temperature on the rheological behavior of orange honey whose viscosity decreased with increasing temperature. Honey was studied in the temperature range $25-45^{\circ} \mathrm{C}$ and humidity of $16 \%, 17 \%, 19 \%$ and $21 \%$.

The rheological behavior is influenced by both humidity and its composition. The activation energy decreases with increasing unity in a similar way to the correlation coefficient.

\section{ACKNOWLEDGMENT}

This research did not receive any specific grant from funding agencies in the public, commercial, or not-for-profit sectors.

\section{Conflicts of Interest}

The authors declare no conflict of interest.

\section{REFERENCES}

1. Ransome, The sacred bee in ancient times and folklore. London: Courier Dover Publications, Dover Books on Antropology and Folklore., 2004.

2. Marghitas L.; Albinele si produsele lor, Editura Ceres, Bucuresti., 2008.

3. Bura M.; Patruica D.; Bura V.A.; Tehnologie apicola, Editura Solness., 2005.

4. Ochi T.; American Bee Journal., 2005. 145(12), 937-938.

5. $\quad$ Cuevas-Glory L.F.; Pino J.A.; Santiago L.S.; Sauri-Duch E.; Food Chemistry., 2007, 103(3), 1032-1043.

6. Pyrzynska I.; Biesaga M.; Trac-Trends in Analitical Chemistry., 2009, 28(7), 893-902.

7. Pohl P.; Trac-Trends in Analitical Chemistry., 2009, 28(1), 117-128.

8. Kaskoniene V.;Venskutonis P.R.; Comprehensive Review of Food Science and Food Safety., 2010, 9(6), 620-634.

9. Vanhanen L.P.; Emmertz A.; Savage G.P.; Food Chemistry., 2011, 128(1), 236-240.

10. Aliferis K.A.; Tarantilis P. A.; Harizanis P.C.; Alissandrakis E.; Food Chemistry., 2010, 121(3), 856-862.

11. Beretta G.; Caneva E.; Facino R. M.; Planta Medica., 2007, 73(15), 1592-1595.

12. Terrab A.; Pontes A.; Heredia F.J.; Diez M.J.; Grana., 2004, 43, 116-121.
13. Tuberoso C.I.G.; Bifulco E.; Caboni P.; Cottiglia F.; Cabras P.; Floris I.; Journal of Agricultural and Food Chemistry., 2010, 58(1), 384-389.

14. Fernández Pierna J.A.; Abbas O.; Dardenne P.; Baeten V.; Biotechnological Agronomic Society., 2011, 15(1), 75-84.

15. Woodcock T.; Downey G.; Kelly J.D.; O'Donnell C.; J. Agricul and Food Chem., 2007, 55(22), 9128-9134.

16. Karoui R.; Dufour E.; Bosset J.O.; De Baerdemaeker J.; Food Chemistry., 2007, 101(1), 314-323.

17. Steffe, J.F. Rheological Methods in Food Process Engineering, Editia a 2-a, Freeman Press, 2807 Still Vallez Dr., East Lansing, MI 48823 USA., 1996.

18. Yanniotis S.; Skaltsi S.; Karaburnioti S. J. Food Engineering., 2006, 72, 372-377.

19. Stanciu I., Orient. J. Chem., 2015, 31(3), 1383-1387.

20. Stanciu I., Orient. J. Chem., 2015, 31(4), 2017-2023.

21. Stanciu I.; Ouerfelli N.; Journal of Biochemical Technology., 2020, 3(11), 52-57.

22. Stanciu I.; Messaâdi A.; Díez-Sales O.; AlJameel S.S.; Mliki E.; Herráez J.V.; Ouerfelli N.; J. Bioch.Tech., 2020, 3(11), 102-114.

23. Stanciu I., J. Sci. Arts., 2018, 2(43), 453-458.

24. Stanciu I., Analele Universitatii "Ovidius" Constanta-Seria Chimie., 2012, 23(1), 27-30. 